\title{
Legitimacy of Entry-Oriented Strategy in DeBakey I Dissection in the Era of Endovascular Therapy
}

\author{
Tamer Ghazy, MD, PhD,${ }^{1}$ Utz Kappert, $\mathrm{MD}, \mathrm{PhD},{ }^{1}$ Ralf-Thorsten Hoffmann, $\mathrm{MD}, \mathrm{PhD},{ }^{3}$ \\ Helena Hegelmann, MD, ${ }^{2}$ Zuzana Fajfrova, MD,${ }^{1}$ Mohamed Eraqi, MD, PhD, ${ }^{1}$ Klaus Matschke, MD, PhD,${ }^{1}$ \\ Norbert Weiss, MD, PhD, ${ }^{2}$ Adrian Mahlmann MD, $\mathrm{PhD}^{2}$ \\ ${ }^{1}$ Department of Cardiac Surgery, Dresden Heart Centre University Hospital; ${ }^{2}$ University Center for Vascular Medicine and Division \\ of Angiology, Department of Internal Medicine III, University Hospital Carl Gustav Carus Dresden ${ }^{3}$ University Center for Vascular \\ Medicine and Institute for Diagnostic Radiology, University Hospital Carl Gustav Carus Dresden, Germany
}

\section{ABSTRACT}

Background: Legitimacy of entry-oriented therapy for DeBakey I aortic dissection is of eminent importance in the era of emerging ascending aorta endovascular therapy. This study aims to evaluate early, midterm, and reintervention results of entry-oriented operative strategy compared to more aggressive strategies for treatment of DeBakey type I aortic dissection with an isolated intimal tear in the ascending aorta.

Methods: This study prospectively followed 98 consecutive patients who received an operation for DeBakey type I aortic dissection with the intimal tear in the ascending aorta between 2007 and 2013 for up to 6 years. Follow-up included survival, medical therapy, CT-imaging results, and reinterventions. Patients were grouped into entry-oriented (group I) receiving an isolated replacement of the ascending aorta and/or hemiarch (65 patients); and aggressive therapy (group II) receiving a replacement of the ascending aorta and complete aortic arch (33 patients).

Results: The in-hospital mortality was $19 \%$ and $23 \%$ respectively. The 3 -year survival was $52 \%$ and $47 \%$ respectively $(P=.193)$. Group II showed no advantage regarding persistence or progression of the dissection, thrombosis of false lumen, increase in aortic diameter, peripheral organ malperfusion (as assessed by follow-up computed tomography imaging) or freedom from reintervention.

Conclusion: In treating DeBakey I aortic dissection with an entry tear in the ascending aorta, it might be legitimate to adopt an entry-oriented operative strategy. Further research is also needed to clearly describe the indication of extending the operative strategy in such cases.

\section{INTRODUCTION}

With an incidence of approximately 2.9/100,000 per year [Isselbacher 2007] and a peak incidence at a mean age of 62 years [Nienaber 2004], acute aortic dissections are knowingly associated with high mortality [Tsai 2009; Hagan 2000]. DeBakey I and II dissections [Debakey 1965] reach

Received November 2, 2016; accepted February 28, 2017.

Correspondence: Dr.med.Tamer Ghazy, Herzzentrum Dresden Universitätsklinik, Fetscherstrasse 76, 01307 Dresden, Germany; +49-351-4501511; fax: +49351-4501512 (e-mail:tamer_ghazy@hotmail.com).
$25 \%$ during the first 24 hours and up to $56 \%$ during the first 30 days if not surgically treated immediately [Daily 1970].

Data from the International Registry of Acute Aortic Dissection (IRAD) [Tsai 2009] showed that an emergency surgical approach could reduce 30-day mortality from more than $56 \%$ to $27 \%$. Nevertheless, perioperative mortality is still high [Tsai 2009; Conzelmann 2011; Easo 2012].

There is no universal surgical strategy for approaching the DeBakey I dissection if the main entry is in the ascending aorta. Some experts believe that a curative therapy should be attempted with resection and grafting of all diseased aortic sections, as possible. Others suggest that surgery should be entry-oriented and tissue, other experts believe that the surgery should be limited to a life-saving procedure excluding the main entry lesion [Truls 2007]. Validating the legitimacy of entry-oriented strategy is getting more crucial in the era of endovascular therapies with the emerging interest in endovascular management of DeBakey type I and II aortic dissections with an endovascular stenting of the ascending aorta.

Several studies have examined perioperative and shortterm outcome after DeBakey I aortic dissections with few follow-up studies [Haldenwang 2012; Legras 2012; Uchida 2013; Hata 2013; Uchida 2011]. However, most reports do not discuss the preferred surgical procedure according to the initial clinical findings. The present study was undertaken to analyze early results and midterm survival, perform a midterm follow-up and determine the need for reintervention after different surgical approaches for DeBakey type I aortic dissections with isolated entry tears in the ascending aorta.

\section{PATIENTS AND METHODS}

\section{Patient Selection}

Between July 2007 and December 2013, 137 consecutive patients underwent emergency surgery in our center for acute DeBakey I aortic dissection and were scanned for inclusion in the study. The inclusion criteria were a documented isolated entry tear in the ascending aorta with no reentries in the aortic arch or the thoracic descending aorta, and undergoing either a replacement of the ascending aorta (AAR) with/ out hemiarch replacmement (HAR), or a complete aortic arch replacement (AR). The study was approved by the local ethics committee, and patients provided informed consent for follow-up. No other exclusion criteria applied. 


\section{Study Groups}

The patient population was divided into two groups according to the performed procedure. Patients in the entryoriented group (group I) were defined as those who received an AAR or HAR, and patients in the aggressive therapy group (group II) were defined as those who received AR.

\section{Baseline Characteristics}

The baseline characteristics of the patient population were collected through history taking, preoperative reports, and clinical examination. Operative risk was estimated using the logarithmic EuroSCORE (log. EuroSCORE) [Nashef 1999].

\section{Surgical Approach}

The surgical procedures performed on the aorta included AAR, HAR, or AR (with or without aortic valve replacement or repair). The decision to either perform an entry-oriented or aggressive approach was at the surgeon's discretion. The replacement procedures were performed in a standard manner. The main surgical strategy included direct innominate artery cannulation, and open aortic repair under moderate hypothermic circulatory arrest with core temperature of $28^{\circ} \mathrm{C}$ with unilateral antegrade cerebral perfusion. In all cases, an aortic valve repair or replacement was performed if a moderate or severe aortic valve insufficiency was documented by echocardiography.

\section{Survival Analysis}

Early mortality was defined as death from any cause within 30 days of the procedure. Midterm survival data were calculated via direct contact with patients, clinic follow-up records, and information from families or referring physicians. All patients who were alive during the period of our study were invited to participate in the follow-up examinations. These included a medical history, assessment of cardiovascular risk factors and comorbidities, and documentation of current medications. A physical examination and imaging studies were performed. According to the follow-up protocol, CT angiography was performed at 3 and 12 months after the initial surgery, or when clinically indicated. Further follow-up imaging was performed between 2 and 3 years after the initial presentation. In case of contraindications to CT imaging, MRIs were performed.

\section{Definitions}

A persistent dissection on the follow-up CT scan was defined as any residual patent false lumen of the aorta. Thrombosis of the false lumen was defined as completely non-perfused and thrombosed false lumen. If the false lumen is not completely thrombosed in any segment, it was defined as partially thrombosed. A complete remodeling was defined as complete regression of the false lumen and regain of the single-lumen aorta. Progression of the dissection during follow-up was defined as a new dissection of a segment of the aorta or any of the aortic branches that was not present at the time of the primary procedure. A diameter increase at the follow-up was defined as an increase in the cross-sectional diameter of the whole aortic thickness, including the thrombosed or perfused false lumen. Freedom from reintervention
Table 1. Preoperative Data

\begin{tabular}{|c|c|c|c|c|}
\hline & Collective & Ascending & Asc. \& Arch & $P$ \\
\hline \multicolumn{5}{|c|}{ Demographics and comorbidities } \\
\hline No. of patients & 98 & 65 & 33 & \\
\hline Age, $y$ & $63 \pm 12$ & $63 \pm 13$ & $65 \pm 11$ & .433 \\
\hline Male sex, n (\%) & $57(58)$ & $35(54)$ & $22(67)$ & .224 \\
\hline Diabetes mellitus, $\mathrm{n}(\%)$ & $12(12)$ & $8(12)$ & $4(13)$ & .978 \\
\hline $\begin{array}{l}\text { Coronary heart disease, } \\
\mathrm{n}(\%)\end{array}$ & $5(8)$ & $2(5)$ & $3(12.5)$ & .253 \\
\hline Renal insufficiency, n (\%) & $66(31)$ & $41(36)$ & $25(22)$ & .161 \\
\hline$>$ COPD, n (\%) & $3(5)$ & $3(7)$ & $0(0)$ & .296 \\
\hline \multicolumn{5}{|c|}{ Clinical presentation and operative risk, $\mathrm{n}(\%)$} \\
\hline $\begin{array}{l}\text { Aortic valve insufficiency } \\
\text { (grade II or higher) }\end{array}$ & $40(41)$ & $24(37)$ & $16(48)$ & .449 \\
\hline $\begin{array}{l}\text { Involvement of } \\
\text { supraaortic branches }\end{array}$ & $48(49)$ & $32(49)$ & $16(48)$ & .780 \\
\hline $\begin{array}{l}\text { Involvement of coronary } \\
\text { ostea }\end{array}$ & $18(18)$ & $11(17)$ & $7(21)$ & .576 \\
\hline $\begin{array}{l}\text { Involvement of visceral } \\
\text { branches }\end{array}$ & $11(11)$ & $9(14)$ & $2(6)$ & .374 \\
\hline $\begin{array}{l}\text { Involvement of renal } \\
\text { branches }\end{array}$ & $18(18)$ & $12(18)$ & $6(18)$ & .661 \\
\hline $\begin{array}{l}\text { Peripheral organ } \\
\text { ischemia }\end{array}$ & $18(18)$ & $12(18)$ & $6(18)$ & .772 \\
\hline Cerebral & $1(1)$ & $2(1)$ & 0 & \\
\hline Cardiac & $2(2)$ & $2(1)$ & $1(3)$ & \\
\hline Renal & $3(3)$ & $3(5)$ & 0 & \\
\hline Multiple splanchnic & $1(1)$ & $1(2)$ & 0 & \\
\hline Lower extremities & $5(5)$ & $4(6)$ & $1(3)$ & \\
\hline Multiple & $6(6)$ & $2(3)$ & $4(12)$ & \\
\hline Neurological deficit & $15(15)$ & $11(17)$ & $4(12)$ & .805 \\
\hline Redo procedure & $13(13)$ & $9(14)$ & $4(12)$ & .812 \\
\hline Log. EuroSCORE & $40 \pm 22 \%$ & $41 \pm 21 \%$ & $40 \pm 24 \%$ & .921 \\
\hline
\end{tabular}

Ascending indicates isolated replacement of the ascending aorta and/or hemiarch; Asc. \& Arch, replacement of the ascending aorta and complete aortic arch; COPD, chronic obstructive pulmonary disease; Log. EuroSCORE, logarithmic European System for Cardiac Operative Risk Evaluation.

was defined as freedom from any open surgical or endovascular therapy related to aortic pathology during follow-up.

\section{Statistical Analysis}

Continuous variables are presented as mean \pm standard deviation. In case of significant outliers, the continuous variables are presented with the median and the $25-75 \%$ interquartile region. Binary data are presented as the percentage of the total study population. Survival curves were 
Table 2. Intraoperative and Postoperative Data

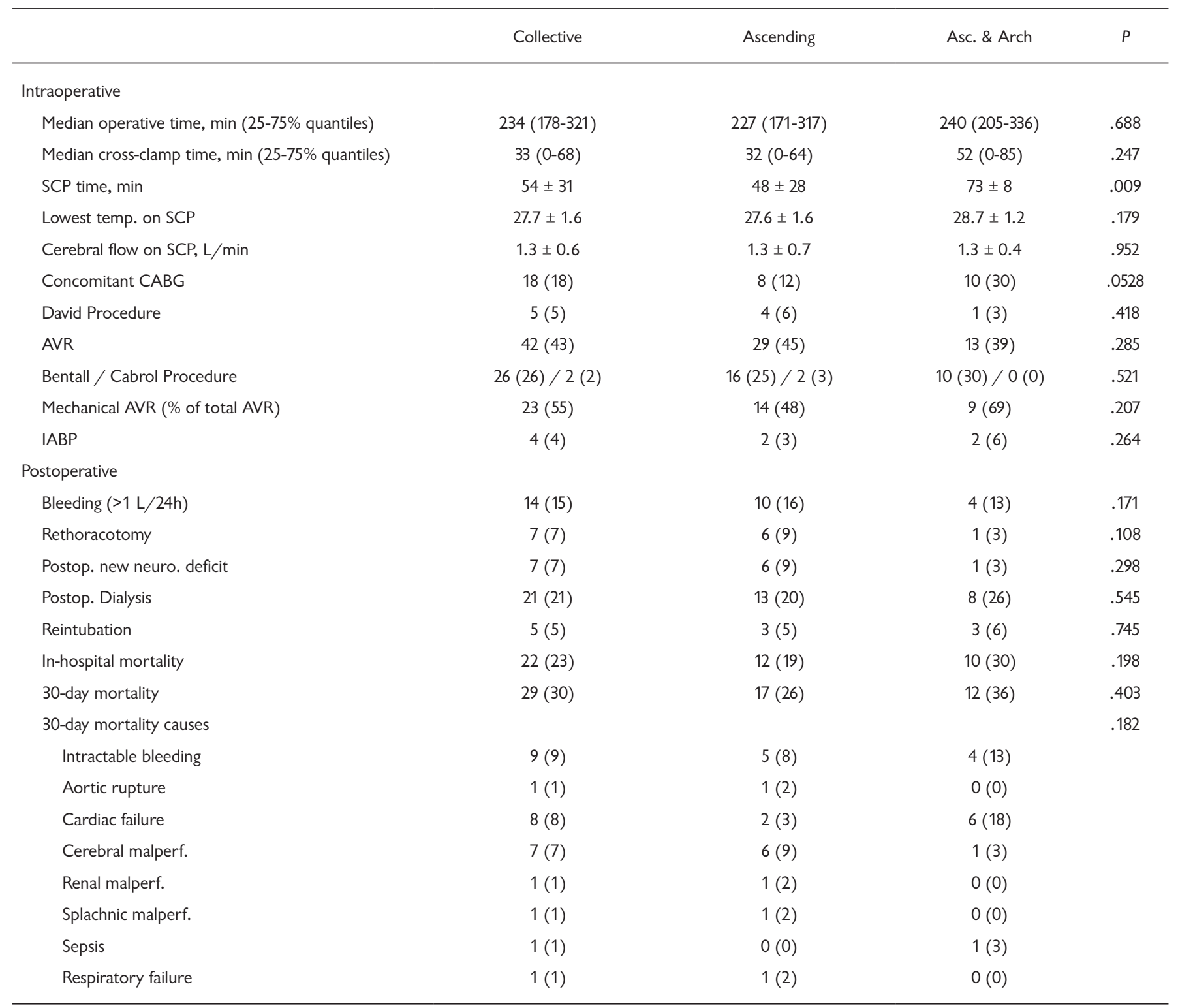

Ascending indicates isolated replacement of the ascending aorta and/or hemiarch; Asc. \& Arch, replacement of the ascending aorta and complete aortic arch; SCP, selective cerebral perfusion; CABG, coronary artery bypass grafting; AVR, aortic valve replacement; IABP, intraaortic balloon pump.

constructed using the Kaplan-Meier method, and the relationships of different surgical procedures to the survival rate were analyzed using the log-rank test. Statistical significance was defined as $P<.05$ (two-sided). All statistical analyses were carried out using JMP (version 6.0.0) software (SAS Institute, Cary, NC, USA).

\section{RESULTS}

\section{In-Hospital Data}

98 patients were included in the study. Baseline characteristics of the patients are presented in Table 1 . The patient population consisted of typical patients at high cardiovascular risk: $19 \%$ presented with peripheral organ ischemia, and $15 \%$ suffered from neurological deficits at the time of surgery. The spectrum of neurological deficits ranged from disorientation to deep coma and from single limb paresis to hemi- or paraplegia. 65 patients received AAR or $\mathrm{HR}$ and were classified as group I, 33 patients received AR and were classified as group II. There were no differences in baseline characteristics or operative risk between the groups (Table 1).

The analysis of intraoperative data (Table 2) showed a median operative time of 234 (178-321), with a significantly shorter selective cerebral perfusion time for group I patients 


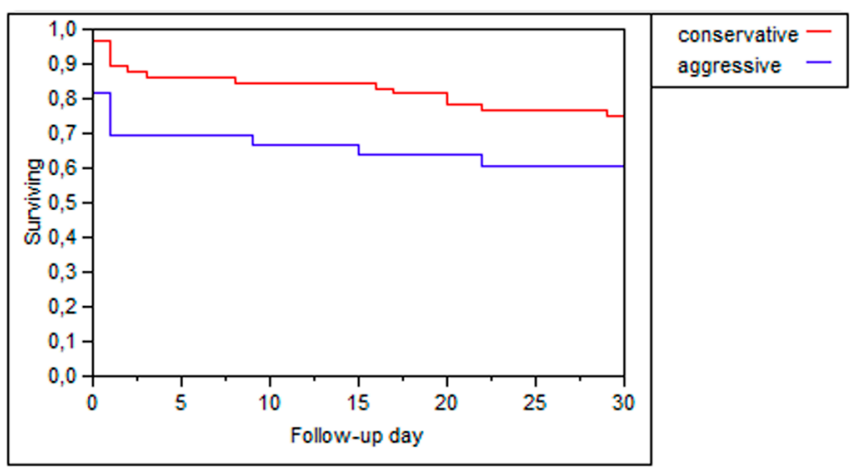

Patients at risk:

\begin{tabular}{|l|l|l|l|l|l|l|l|l|}
\hline Day & 0 & 1 & 5 & 10 & 15 & 20 & 25 & 30 \\
\hline Collective & 98 & 90 & 80 & 77 & 76 & 73 & 71 & 69 \\
\hline Conservative & 65 & 63 & 57 & 55 & 53 & 52 & 50 & 49 \\
\hline Aggressive & 33 & 27 & 23 & 23 & 22 & 22 & 21 & 21 \\
\hline
\end{tabular}

Figure 1. The 30-day survival. Kaplan-Meier survival curves were calculated according to the surgical procedure performed for each group. There were no statistically significant differences.

$(48 \pm 28$ versus $73 \pm 8, P=.0099)$. Other than that, there were no significant differences between the groups.

Postoperatively (Table 2), 7\% of patients had to be reoperated for bleeding and/or tamponade, $7 \%$ had neurological deficit, $21 \%$ needed dialysis. Reintubation was necessary in $5 \%$ of patients. There were no statistical differences between the groups.

\section{Early Survival}

The overall in-hospital mortality was $23 \%$ (19\% for group I, 30\% for group II, $P=.198$ ). The 30-day survival was $70 \%$, which concurs with published results from other registries [Uchida 2009; Nashef 1999; Omura 2016]. The 30 -day survival rate was higher in group I (74\%) than group II (60\%), though the difference was not statistically significant $(P=.182)$ (Figure 1). Causes of early deaths are listed in Table 2. $30 \%$ of early deaths were due to intractable bleeding or aortic rupture; $58 \%$ of deaths were due to organ malperfusion. There were no significant differences between the groups.

\section{Midterm Results: Survival Data}

Among the 69 30-day survivors, 4 patients were lost to follow-up. Survival data were compiled for 65 patients, comprising $94 \%$ of survivors. The overall 1,000-day survival was $50 \%$ of the total number of operated patients. 50 patients survived the follow-up period, with a mean follow-up of $1417 \pm 816$ days and a total follow-up of 235 patient years. The survival rate of group I patients was better than that of group II (52\% and $47 \%$, respectively), though this was not statistically significant $(P=.193)$ (Figure 2$)$.

\section{Imaging Studies and Follow-up Results}

Among the 50 surviving patients, follow-up imaging studies were performed in 41 patients (29 patients in group I, 12 patients in group II; $82 \%$ of survivors) after a mean follow-up period of $1492 \pm 756$ days and a total follow-up time of 167

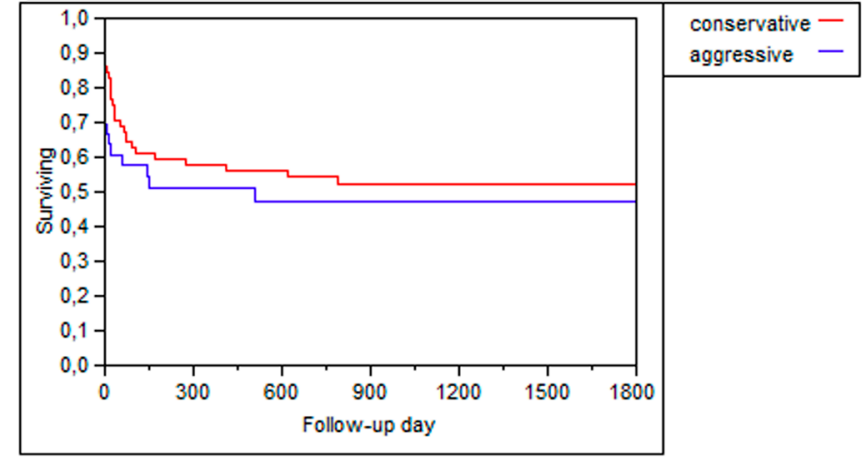

Patients at risk:

\begin{tabular}{|l|l|l|l|l|l|l|l|}
\hline Day & 0 & 300 & 600 & 900 & 1200 & 1500 & 1800 \\
\hline Collective & 98 & 51 & 42 & 37 & 32 & 26 & 24 \\
\hline Conservative & 65 & 37 & 30 & 25 & 22 & 16 & 16 \\
\hline Aggressive & 33 & 15 & 13 & 13 & 11 & 11 & 9 \\
\hline
\end{tabular}

Figure 2. Midterm survival. Kaplan-Meier survival curves were calculated according to the surgical procedure performed for each group. Aggressive surgical strategy continued to show lower survival rates at the midterm, yet the difference stayed statistically nonsignificant.

patient years. The remaining patients declined the follow-up imaging studies.

\section{Persistence of Dissection}

As shown in Table 3, the total incidence of persistent dissection was $41 \%$. The analysis did not show a statistical difference between the study groups $(P=.158)$. Group I showed a higher rate of complete thrombosis of the false lumen than group II, which showed a higher rate of false lumen partial thrombosis, with no statistical significance $(P=.679)$.

\section{Dissection of the Aortic Branches}

The statistical analysis showed no persistent dissection of the coronary arteries. Dissections of the supraaortic, renal, and visceral branches were detected in $35 \%, 40 \%$ and $10 \%$ of patients respectively, with no statistical differences between the groups (Table 3).

\section{Progression of Dissection}

As shown in Table 3, the total incidence of dissection progression during follow-up was $20 \%$, with no statistical difference between the groups $(P=.574)$.

\section{Increase in Aortic Diameter}

In group I patients, $18 \%$ showed an increase in the aortic diameter during follow-up (Table 3). In group II patients, the total incidence of further aortic distension was $17 \%$, with no statistically significant difference $(P=.288)$.

\section{Peripheral Organ Malperfusion}

Peripheral organ malperfusion was detected in 2 patients (5\%). They were malperfusions of one of the kidneys. They were all in patients in group I, with no statistical significance $(P=.412$ (Table 3$)$. 
Table 3. Imaging Results

\begin{tabular}{lcccc}
\hline & Collective & Ascending & Asc. \& Arch & $P$ \\
\hline Total number of patients & 41 & 29 & 12 & \\
Persistent dissection & $17(41)$ & $10(34)$ & $7(58)$ & .158 \\
State of the false lumen & & & & .679 \\
$\quad$ Completely thrombosed & $9(30)$ & $7(33)$ & $2(22)$ & \\
Partially thrombosed & $10(33)$ & $6(29)$ & $4(44)$ & \\
Patent & $11(37)$ & $8(38)$ & $33 \%(3)$ & \\
Dissection of aortic branches & & & & \\
$\quad$ Coronary arteries & 0 & 0 & 0 & \\
Supraaortic branches & $14(35)$ & $11(39)$ & $3(25)$ & .385 \\
$\quad$ Visceral branches & $4(10)$ & $2(7)$ & $2(16)$ & .183 \\
$\quad$ Renal branches & $16(40)$ & $12(43)$ & $4(33)$ & .573 \\
Renal malperfusion & $2(5)$ & $2(7)$ & $0(0)$ & .412 \\
Progress of dissection & $8(20)$ & $6(21)$ & $2(17)$ & .574 \\
Increase of aortic diameter & $7(17)$ & $5(17)$ & $2(17)$ & .641 \\
\hline
\end{tabular}

Ascending indicates isolated replacement of the ascending aorta and/or hemiarch; Asc. \& Arch, replacement of the ascending aorta and complete aortic arch.

\section{Freedom from Reintervention}

The overall 3-year freedom from reintervention rate was $95 \%$ (Figure 3). This rate was $92 \%$ in group I and $100 \%$ in group II. The 6-year freedom from reintervention rate was $78 \%$ with no statistical significance between group I and group II ( $86 \%$ versus $65 \%$ respectively, $P=.626)$. Table 4 lists the detailed reintervention data.

The univariate analysis of putative factors that increase the risk for reintervention showed a significant influence of presence of aortic valve insufficiency or aortic arch aneurysm at the time of the primary procedure $(\mathrm{P}=.032$ and .042 respectively). The significant risk factors in the follow-up period were the presence of aortic arch aneurysm and the increase in the aortic arch diameter over the follow-up period $(\mathrm{P}=.022$ and .008 respectively). However, multivariate analysis did not reveal any independent risk factor associated with higher reintervention rates.

\section{DISCUSSION}

Analysis of the results revealed that irrespective of the operative strategy, the acute dissection still carries a high early mortality risk, which concurs with published data [Tsai 2009; Conzelmann 2011; Easo 2012].

Our follow-up results showed that patients who underwent a more extended operation compared to excision and grafting of the ascending aorta alone did not show a significant lower rate of persistent or progression of the dissection, diameter increase, or reintervention, which is the main objective of the aggressive strategy. These data suggest that an entry-oriented

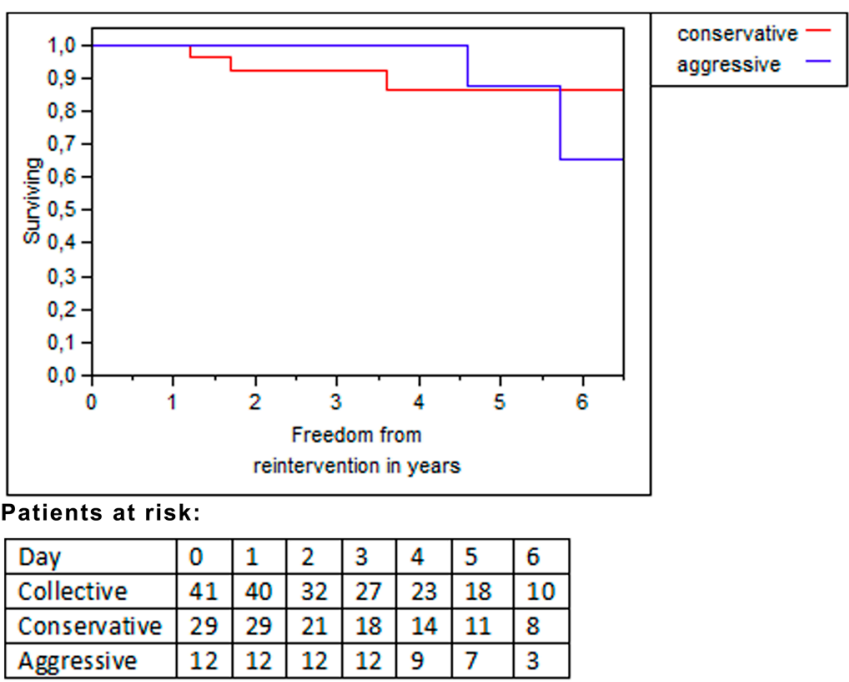

Figure 3. Kaplan-Meier curves for freedom from reintervention during the follow-up period of up to 6 years. Aggressive surgical strategy failed to maintain its superiority and dropped below the conservative strategy after 5 years.

approach in patients with isolated entry tear in the ascending aorta might be sufficient in the acute setting.

The debate on the optimal extent of the surgery in DeBakey type I aortic dissection is an ongoing process. Estrera and his colleagues [Rice 2015], Okita and the Kobe group [Omura 2016] and Dr. Di Eusanio and the Bologna group [Di Eusanio 2015] published different data supporting an entry-oriented approach. The above-mentioned data concurs with our results.

In the era of emerging endovascular therapy for the ascending aorta, validating an entry-oriented approach for the treatment of DeBakey I is of eminent importance. Based on the results of this study, we believe that an entry-oriented endovascular stenting of the aorta for DeBakey type I dissection could be a legitimate option to be developed. Although this therapeutic option is still in the early phase, promising initial results are emerging [Nienaber 2017].

\section{Study Limitations}

The study was based on a single institution's data. The study was based on a prospective registry with no randomization of the cases. Procedure selection bias may have existed according to the performing surgeon. Four frozen elephant trunk patients were excluded due to low statistical power of that group. The causes of late deaths could not be acquired. The long-term outcome data are yet to be obtained.

\section{Conclusion}

In treating DeBakey I aortic dissection with the entry tear in the ascending aorta, it might be legitimate to adopt an entry-oriented operative strategy. Extending the surgical therapy in such cases might not provide a clear short or midterm survival benefit, improve the midterm imaging findings, or significantly reduce the reintervention rates in midterm. 
Table 4. Reintervention

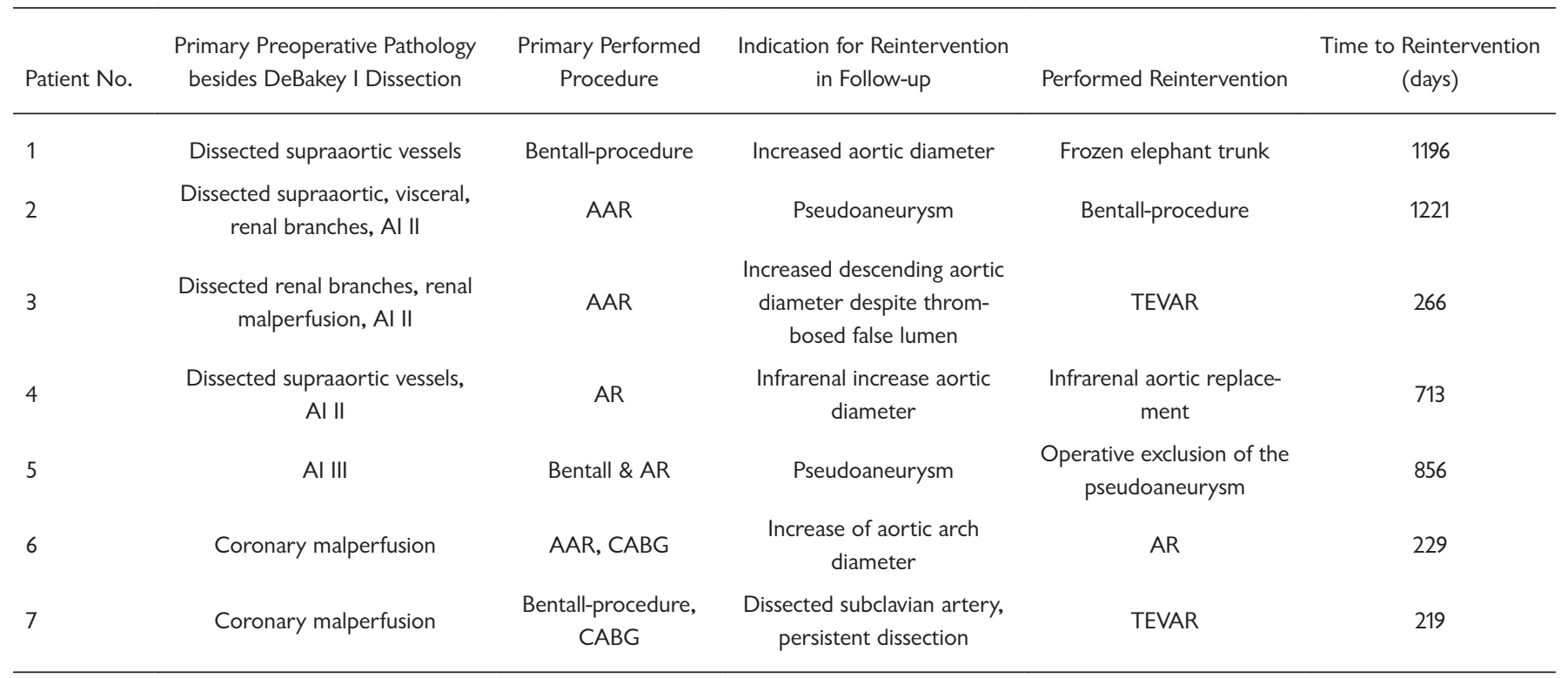

Al indicates aortic valve insufficiency; AAR, replacement of the ascending aorta; TEVAR, thoracic endovascular aortic repair; AR, complete aortic arch replacement; $C A B G$, coronary artery bypass grafting.

Further research is needed to clearly describe the indication of extending the operative strategy in such cases.

\section{REFERENCES}

Conzelmann LO, Kruger T, Hoffmann I, et al. 2011. German Registry for Acute Aortic Dissection Type A (GERAADA): initial results. Herz 36:513-24.

Daily PO, Trueblood HW, Stinson EB, Wuerflein RD, Shumway NE. 1970. Management of acute aortic dissections. Ann Thorac Surg 10:237-47.

Debakey ME, Henly WS, Cooley DA, Morris GC Jr, Crawford ES, Beall AC Jr. 1965. Surgical management of dissecting aneurysms of the aorta. J Thorac Cardiovasc Surg 49:130-49.

Di Eusanio M, Berretta P, Cefarelli M, et al. 2015. Total Arch Replacement Versus More Conservative Management in Type A Acute Aortic Dissection. Ann Thorac Surg 100:88-94.

Easo J, Weigang E, Holzl PP, et al. 2012. Influence of operative strategy for the aortic arch in DeBakey type I aortic dissection: analysis of the German Registry for Acute Aortic Dissection Type A. J Thorac Cardiovasc Surg 144:617-23.

Hagan PG, Nienaber CA, Isselbacher EM, et al. 2000. The International Registry of Acute Aortic Dissection (IRAD): new insights into an old disease. JAMA 283:897-903.

Haldenwang PL, Wahlers T, Himmels A, et al. 2012. Evaluation of risk factors for transient neurological dysfunction and adverse outcome after repair of acute type A aortic dissection in 122 consecutive patients. Eur J Cardiothorac Surg 42:e115-20.

Hata M, Akiyama K, Hata H, et al. 2013. Early and midterm outcomes of quick proximal arch replacement with mild hypothermia and rapid rewarming for type A acute aortic dissection. J Thorac Cardiovasc Surg 146:119-23.
Isselbacher EM. 2007. Epidemiology of thoracic aortic aneurysms, aortic dissection, intramural hematoma, and penetrating athersclerotic ulcers. In: Eagle KA, Baliga RR, Isselbacher EM, Nienaber CA, eds. Aortic dissection and related syndromes. New York: Springer Science+Business Media. pp. 3-16.

Legras A, Bruzzi M, Nakashima K, Hillion ML, Loisance D, Kirsch M. 2012. Risk factors for hospital death after surgery for type A aortic dissection. Asian Cardiovasc Thorac Ann 20:269-79.

Nashef SA, Roques F, Michel P, Gauducheau E, Lemeshow S, Salamon R. 1999. European system for cardiac operative risk evaluation (EuroSCORE). Eur J Cardiothorac Surg 16:9-13.

Nienaber CA, Fattori R, Mehta RH, et al. 2004. Gender-related differences in acute aortic dissection. Circulation 109:3014-21.

Nienaber C, Sakalihasan N, Clough R, et al. 2017. Thoracic endovascular aortic repair (TEVAR) in proximal (Type A) aortic dissection: ready for a broader application? JCTVS 153:S3-S11.

Omura A, Miyahara S, Yamanaka K, et al. 2016. Early and late outcomes of repaired acute DeBakey type I aortic dissection after graft replacement. J Thorac Cardiovasc Surg 151:341-8.

Rice RD, Sandhu HK, Leake SS, et al. 2015. Is total arch replacement associated with worse outcomes during repair of acute type A aortic dissection? Ann Thorac Surg 100:2159-65.

Truls M, Santi T, Vincenzo R. 2007. Cardiovascular surgery in the initial treatment of aortic dissection and acute aortic syndromes. In: Eagle KA, Baliga RR, Isselbacher EM, Ninaber CA, eds. Aortic dissection and related syndromes. New York: Springer Science+Business Media. pp. $167-90$.

Tsai TT, Trimarchi S, Nienaber CA. 2009. Acute aortic dissection: perspectives from the International Registry of Acute Aortic Dissection (IRAD). Eur J Vasc Endovasc Surg 37:149-59. 
Uchida N, Shibamura H, Katayama A, Shimada N, Sutoh M. 2009. Total arch replacement with an open stent graft for acute type A aortic dissection: fate of the false lumen. Eur J Cardiothorac Surg 35:83-8.

Uchida N, Katayama A, Tamura K, Sutoh M, Kuraoka M, Ishihara H. 2011. Frozen elephant trunk technique and partial remodeling for acute type A aortic dissection. Eur J Cardiothorac Surg 40:1066-71.

Uchida N, Katayama K, Takahashi S, Sueda T. 2013. Endovascular stent grafting of the downstream aorta after complete arch replacement using the frozen elephant trunk technique for acute type A aortic dissection. Eur J Cardiothorac Surg 43:196. 